\title{
Brand Naming Behavior Defining SMMEs in eThekwini
}

\author{
Lindiwe N. Kunene*, Maxwell Phiri \\ University of KwaZulu-Natal, South Africa \\ Kunenel3@ukzn.ac.za*, phirim@ukzn.ac.za
}

\begin{abstract}
Branding is an integral part to the success of any and every business. Appropriate brand strategies contribute to brand equity of the organization leading to increased turnover and profits of positive turnover for organizations. Application of properly planned brand naming processes could save SMMEs and reduce the high failure rate experienced by this sector, in South Africa currently. Branding helps businesses to define who they are and guides their overall strategy. Branding strategies begin with the brand naming process. There are scientifically proven models that govern this process which have been used by successful businesses, globally. This study sought to find the current brand naming processes as implemented by SMMEs in the eThekwini Municipality area in Durban, South Africa. This was the first step in developing a model for brand naming for SMMEs in eThekwini. The study therefore used descriptive-exploratory ethos to conduct the research, guided by the epistemological, ontological and axiological assumptions. Demographic dimensions, ownership of the brand naming process, traits in the naming process and brand naming strategies considered were used to reach conclusions that define these entities in eThekwini. Research outcomes found that a lack of resources and knowledge were the main impediments distorting appropriate brand naming processes.
\end{abstract}

Keywords: Brand Naming Processes, Marketing, Entrepreneurship

\section{Introduction}

The branding process for Small, Medium, Micro Enterprises (SMMEs) is one that is faced with barriers, ranging from the expense of branding to legal regulations. Phiri (2009) warns that the 'autocratic' rules that define SMMEs in this country should be removed and redefined to avoid them being hindrances and instead, making them catalysts that promote and accelerate the growth of SMMEs. The marketing process which branding is a function of is at times regarded as cumbersome, resulting in stagnant development in the SMME sector. Research concluded in South Africa (SA) has found that SMMEs tend to apply reactive marketing strategies and fail to be innovative, hurting their sustainability (Makhitha, 2009). A good marketing strategy cannot be implemented without the existence of a brand position and strategy. SMMEs are aware of the need and the use of marketing; however, they do not apply these strategies, adding to the distortion of growth. This paper seeks to understand and explore the first phase of marketing, which is branding for SMMEs in eThekwini. The purpose is to examine brand naming processes used by these entities and ascertain if a correct process is used. The research, on which the paper is based, had the following aims to fulfill:

- To find out about Brand Naming strategies used by eThekwini SMMEs.

- To establish who the Brand Naming custodians are and their responsibilities.

- To find out the role of demographic dimensions in the Brand Naming process in SMMEs.

In eThekwini Municipality, like in most of SA, SMMEs are strategic in achieving the economic goals of the city achieve economic growth in the city, (Naidoo, 2008). According to the Global Economic Monitor (GEM), the failure rate for these organizations in the country is $90 \%$ (GEM, 2014). Government, both local and national have over the years developed skills training programs to assist SMMEs. Despite this, SMMEs are still closing down. This unfortunate phenomenon in cases where seed funding has been secured raises other questions about the failure of SMMEs. Keller (1998) and Aaker (1996) support the view of the development of branding; their work constantly supports the need for creation of a valued brand for trading businesses. Without branding, businesses competing in a 'free choice society' will not succeed. SA has been growing in a diverse cultural background and has potential for further growth in the years to come (Mthoba, 2004). South Africa is regarded as a developing one, having recently moved from an unequal system of apartheid to one which is trying to address the economic equality of all its' citizens, despite the racial disharmony which still exists, caused by race segregation laws known as apartheid. The system of apartheid saw skewed division of resources based on racial lines. This being the case, there has to be strategies and policies in place created and implemented by government to support and encourage growth, (Brand, Du Preez and Schutte, 2007), 
without racial divisions, rectifying the injustices of the past. This has become eminent in recent years due to the economic crisis occurring globally and impacting world economies.

According to Naidoo (2007), 50\% of the countries' economic growth is due to small medium and micro enterprise (SMME). It is therefore imperative that the role of SMMEs is fully supported and developed accordingly, for the overall benefit of the citizens of this country, especially when predictions had been set at $6 \%$ growth rate annually and halving of unemployment by 2014 (Mthoba, 2004), and this was not reached. The Global Entrepreneurial Monitor states that developing countries need to promote entrepreneurial enterprise in order to promote economic growth (Parkin, Powell \& Mathews, 2008). The root of branding is in the name, without which there can be neither brand strategy nor a marketing plan and entrepreneurial enterprises would not survive. Canada and the United Kingdom are considered leaders in strategy and policy formulation in Small Business Development (Stevenson \& Lundstrom, 2001). These countries realized before many others that there was a rapid growing culture of small business start-ups, as such, governments needed to be active in managing this asset and strategizing for it accordingly (Stevenson \& Lundstrom, 2001). Since 1994, SA has actively been involved in support strategies and policy formalization for small businesses. This practice has led to various initiatives, some refined from the previous government, while some from the current government. These programs which are governed by the Department of Trade and Industry and recently the department of Small Business Development have been fundamental in providing support to SMMEs. These programs are designed to develop these entities and assist them in avoiding failure. However, most of these entities still fail despite these efforts.

Researchers in the field of SMMEs identify finance as one of the vital support structures that underlie the failure rate of SMMEs. This failure includes financial knowledge and practice by SMME owners/managers (Struwig, 2011).Failing to find adequate markets is another area that leads to failure, Visagie (1997) and Eku, (2007) blame poor marketing and branding for this. They suggest that once products are not packaged and branded adequately they stand little chance in competing nationally and internationally. Brand naming is therefore critical in achieving the latter. The brand naming process lacks academic discourse and is not synonymous with branding strategy, though related. However, this is changing as interest grows. The reason for interest can be accrued to the fact that the little research there is, emphasizes the importance of appropriate brand naming strategies and how it cannot be ignored as it has the propensity to significantly add value to organizations (Kohli \& Suri, 2000). That being the case, the concept of branding is dependent on the brand naming process for it to be regarded as suitable and of value for an organization.

The strength of a brand is what makes a product, service or retailer successful. Thus the consequence of a successful brand provides consumers with what they require and demand in consumables, and it yields benefits required by consumers' (Keller, 2003). Researchers such as Abimbola (2001), Keller (2003) agree and advise that small businesses need to have strong brand management system to perform well in the context of their economies. Such action creates wealth for the business and its shareholders. 'A brand name is an asset; it adds value to the organization' (Kering \& Sethuraman, 1998, p. 2). If brands are assets for their organizations they are of economic significance to them. It is for this reason that branding should not be regarded as a mere concept within marketing; however, it should be seen as a function that has a significant role in an organization and its ability to generate a profit.

Branding and SMMEs: Paucity in literature for brand naming processes in SMMEs is a problem this study seeks solve. Berthon, Ewing and Napoli, (2008) argue that with regards to SMMEs such research is limited. This limitation is further intensified by the fact that the study of brand naming strategies has limited research for all business forms, only the corporate business forms, are usually investigated with regards to this phenomenon. Recorded failure of SMMEs is found to be more prevalent in black owned enterprises (Dube, 2001). This is as a result, amongst other problems of poor education and economic structures for none-white races, a practice which succeeded through domination and control for centuries in South Africa (Wolpe, 1972). According to Meyer-Stemer (2003) without branding, adequate branding, visibility of an SMME becomes questionable, so does its existence. Below is a depiction in Figure 1, which shows that low-visibility, mostly achieved by a brand, leads to difficulty in achieving success for your business. 


\section{Figure 1: Some Obstacles for Entrepreneurship in SA}

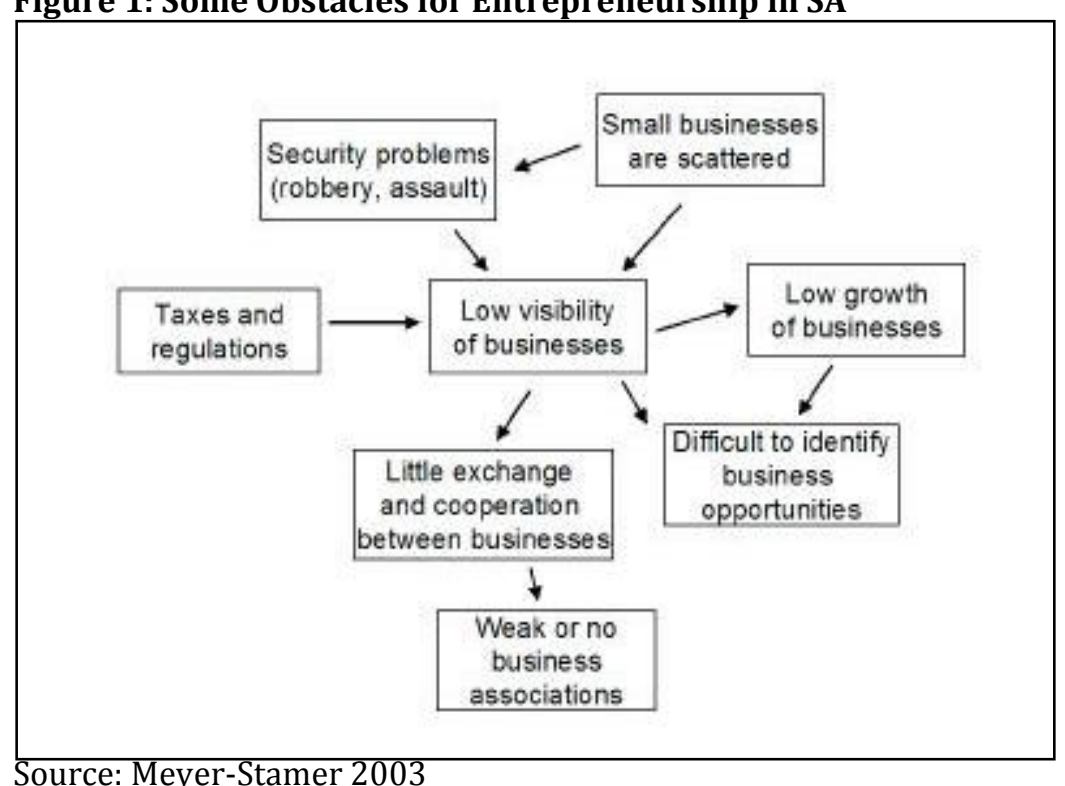

The most influential hindrance in the branding processes for SMMEs lies in the lack of abundant financial reserves, (Wong \& Merrilees, 2005). Small firms have limited financial reserves, with limited human resources, as well as limited time. This makes it difficult for these entities to engage with branding as they should. This as Wong and Merrilees (2005, p 404) pointed out is perpetuated by the fact that in these entities' branding is informal, possibly even optional, involving a narrow range of promotional tools' in SMMEs and suggests that this results in failure.

\section{Literature Review}

When reviewing most literature on branding, one discovers that there is dearth in literature defining brand naming strategies for SMMEs. For instance, Kotler (2003) in his research only ever approached the concept for brands that already exist and are looking to extend their line or redefine them. Such thinking is similar to that by a world known author on branding, Kaperer (2004), whose advice on brand naming strategies is designed for extensions. One thing is for certain, both these authors place an emphasis on exclusivity and uniqueness in branding (Kotler, 2003; Kapferer, 2004), which can only be achieved through a choice of an adequate brand name. Creation of a brand requires a complicated decision making process as whatever name is finally chosen will over time, embody the product for that entity which it was created for (Kohli \& LeBahn, 1995). Researchers such as Vanden Burg, Adler and Oliver (1987) have in the past and currently, been compiling and completing research to study what the meaning of the branding process is, linguistically, culturally and in the context of the business environment. Their research has pioneered and developed theories that further seek to understand the brand naming processes and/or strategies.

Roszokwski in (2013) postulates that, to have a brand name or rather to choose a brand name is a process embedded in the concept of memory. Ease of recall and the ability to easily encode a brand name and ability to remember are of the essence for the brand naming purposes. Guided by the need to achieve ease of recall, McNeal and Zaren (1981) and later Shipley, Hooley and Wallace (1988) agreed that to build a brand that carried ease of recall, and stuck to memory required a process to be designed and followed. Such a process would need certain vital stakeholder to be consulted in order for it to be completed and for it to carry the ease of recall and memory factors that had been raised by researchers into the brand naming process. Boyd in 1985 introduced alphanumeric theories as a significant factor in achieving memory and ease of recall (Boyd, 1985).In 1995, improving on already existing theories, Kohli and Lebahn (1995) then created a six stage process that considered linguistics and stakeholder involvement in the creation of a brand naming process. Regardless of who names the brand, the success of an organization is embedded on an adequate brand name. It is vital to note and advise all SMMEs that, where the brand name chosen has no inherent meaning, large 
amounts of resources would be required to promote the brand (Turley \& Moore, 1995). Large amounts of funds are not a favorable scenario, therefore Kohli and LeBahns's (1995) study on Effective Brand Naming Processes is one that can minimize incurring high costs when establishing a brand name.

Their theory is combined with work completed by Kollman and Suckow (2007) and later Roszkowski (2013) to create a robust study that has considered varied perspectives to assist SMMEs. Proposition put forward by Kohli and LeBahn's (1995) identified Branding objectives; sometimes referred to as brand naming objectives was explained as the establishment of a specific image and position. These objectives are used in the construction of the six step process of brand naming. They are:

- Branding Criteria; referred to the brand name being compatible with the brand image as well as memorability.

- Generation of New Brand names; creation of a 'long list of possible names' (Kohli \& LaBahn, 1995, p 16)

- Screening the name appropriateness; from the process above, choosing the names that are more suitable.

- Researching consumers' preferences; through the application of various research methods in which the most preferred names should be selected

- Conducting a trademark search; submission of four or five chosen names to the patent and/or trademark office for registration. Submitting more than one guard against the possibility of the name you want already being unavailable.

One of the first and foremost drivers of brand naming as discussed by most authors including Kohli and LeBahn (1995) and Roszkowski (2013) is embedded on the notion that brand naming stems from the understanding and use of brand naming. When reviewing literature on branding strategies, Robertson (1992) as cited by Angus and Oppenheim (2004) divulge various traits that are important when brand naming, amongst these traits they place an emphasis on simplicity, meaningfulness and distinctiveness. These traits are also discussed by Kohli and LeBahn's (1995), they label them as: (1) Ease of Pronunciation, (2) Consistency with image, (3) Ease of Recognition, and (4) the relationship between the chosen brand and business activity, which are central to this study.

The question of who is going to brand is essential. To solve this, the question that should be posed is, whose task is it to allocate a brand name? Is this the task of the employees, founders, customers and/or suppliers? For most large corporations who have financial resources, they can afford to have a marketing department which has the autonomy to invest on consumer research and varied legal and other form of agencies in their quest to find the appropriate brand name. McNeal and Zaren, (1981) found that most of the Fortune 500 companies use the marketing departments in choosing a brand. In a study conducted by Shipley, Hooley and Wallace (1988) in the UK (United Kingdom) supported this thinking in their research as they found that brand naming was a task that should be performed by the marketing and the executive management team, where possible, in consultation with legal and other agencies as mentioned above.

In South Africa, there are a number of avenues from the legal perspective that are made available to organizations to register their business entities. All organizations have to follow the provisions by the companies act. This act uses the CIPC to assist with the registration process, CIPC stand for Companies and Intellectual Property Commission, (CIPC, 2016). Registering with the CIPC however does not guarantee legal protection of a brand name until such time as when the appropriate name is selected and a number is allotted to the organization, (Companies Act of 2008 as cited by the CIPC (2016)). Organizations are however still expected to register their copyright protected name after this process with CIPC.

\section{Methodology}

Sekaren and Bougie (2010) stipulate that exploratory methodology be applied when there is limited information in that particular field, and where there is dearth in describing the knowledge of the phenomenon being studied. This research is descriptive exploratory research; it borrows from the ethos of both exploratory research and descriptive research. What is researched needed to be understood, without interference (Hair, Anderson, Tatham \& Black, 1998; Babbie \& Mouton, 2006). Due to the importance of the 
generalizability of the study. The study design is embedded on, (1) ontological assumptions, that stress that the reality of the research should be objective;(2) epistemological assumption, where the researcher is independent from that which is being researched and (3) an anxiological assumption, which 'stressed the unbiased nature of quantitative research applied' as cited by Creswell (2003, p 5).It is on this premise that quantitative methods of research were used to conduct this research where statistical inferences implemented eliminated the possibility of human preferences and perceptions that could influence the data captured and the analysis thereof (Cant, Gerber, Nel \& Kotze, 2003).

Firstly, according to Morgan and Smircich (1980) as cited by (Matveev, 2002) quantitative research is based on the assumption that social reality has an objective ontological structure and that individuals are responding agents to this objective environment. This paradigm exists on the notion that the measure of 'being' is that which can in fact be measured scientifically (Matveev, 2002). Secondly, quantitative research was chosen as it allows for the analysis of data to take place without contact with the respondents. The sample was selected within the geographical area of eThekwini Municipality. This area includes the actual CBD (Central Business District) and the surrounding residential and industrial suburbs as well as locations/townships. The SMMEs were approached by field workers individually, to complete the questionnaires. SMMEs approached were sourced through availability and consent to participate. No distinction was made between formal and informal SMMEs as they both were active participants in the economy of Durban. The final population size of SMMEs in the area is unknown; the Durban Chamber of Commerce estimated the population size to be at around 3000, an estimation based on their registered membership. Due to this, non-probability sampling would have to be the chosen sampling technique. For convenience purposes and accessibility to be achieved.

Given the size of the estimated population, a sample was used to represent the population. Based on the population of 3000.A 341 sample size was therefore determined by Sekaren and Bougie (2010) sampling table, making up ten percent of the population. Data analysis allows for inferences to be deduced about the data with the purpose of describing the phenomenon (Frank \& Althoen, 1994). According to Frank and Althoen (1994), it is important, in the collections phase that there are no preconceived ideas about the phenomenon being researched, influencing the statistics. Pearson's Correlation analysis in its application has an implied support of this notion as it allows for as many variables as possible, thus giving rise to the data guiding the research itself without the researcher influence, (Frank \& Althoen, 1994). Cronbach's Alpha was used to test for reliability and a test re test method of validity testing.

\section{Results and Discussion}

As manifested by this study the following traits were found to be relevant in the brand naming process by SMMEs; Ease of Recognition, Ease of pronunciation, the relationship between the chosen brand and business activity and consistency with image. These are part of the first objective of the study which asked, what the most prevalent brand naming strategies for SMMEs in the eThekwini area were. The research found that the most important strategies in brand naming, scoring at a percentage of $80.5 \%$ by the respondents was; the relationship between chosen brand and the business activity. This trait was followed by Ease of recognition at $71.6 \%$ and Consistency with image distribution at $65.8 \%$. The trait that appears last is the Ease of Pronunciation at $44.7 \%$.

On the question of brand naming objectives and decisions. Six traits as per Kohli and LeBahn (1995) research were found to be important to SMMEs. For purposes of conceptualizing the brand naming phenomenon further, it was vital to use correlation to establish relationships that exist and define the brand naming process. In the studies previously conducted on this phenomenon by Kohli and LeBahn (1995) correlation was conducted to compare and contrast relationships amongst significant brand naming criteria. The correlation (r) between the existing name purchased from another company and the existing name of another company product was found to be -0.081 . This coefficient showed that there was a weak relationship between the existing name purchased from another company and the existing name of another company product. The probability (p) of this correlation coefficient which is 0.539 is greater than 0.05 thus implying that there is no statistically significant relationship between the existing name purchased from another company and the existing name of another company product $(r=-0.081, p>0.05)$. 
Consistency with existing product line and consistency with company image has an $r$ value of 0.597 . This coefficient depicts that there is a strong and positive relationship between consistency with existing product line and consistency with company image. The probability of this correlation coefficient was 0.000 , less than 0.05 thus implying that there is a statistically significant relationship between consistency with existing product line and consistency with company image $(r=-0.597, p>0.05)$. This strong relationship proved the impact that the product offering and company image has on the final decision making process for SMME brand names. The correlation ( $r$ ) between ease of recognition and overall liking was found to be 0.667 . This coefficient depicted that there was a strong and positive relationship between ease of recognition and overall liking. The probability (p) of this correlation coefficient which was 0.000 is less than 0.05 thus implying that there is a statistically significant relationship between ease of recognition and overall liking $(\mathrm{r}=-0.667$, $\mathrm{p}>0.05$ ). SMMEs are found, in this research, to relate recognition and overall liking of brand names chosen. This relationship therefore has a significant impact in the decision process of the brand naming process.

The correlation (r) between relevance for product category and connotations was found to be 0.289 . This coefficient showed that there is a strong and positive relationship between relevance for product category and connotations. The probability (p) of this correlation coefficient, which is 0.006 , is less than 0.05 thus implying that there is a statistically significant relationship between relevance for product category and connotations $(r=-0.289, p>0.05)$ Connotations that are related to the SMME and the type of product offering had a relationship and found to be relevant in the brand naming process. Correlation ( $\mathrm{r}$ ) between distinctive and profane or negative connotation was 0.301 . The coefficient showed that there is a strong and positive relationship between distinctive or profane and negative connotations. The probability (p) of this correlation coefficient which is 0.006 was less than 0.05 thus implying that there is a statistically significant relationship between distinctive and profane or negative connotation $(\mathrm{r}=-0.301, \mathrm{p}>0.05)$. SMMEs viewed that which is profane to have a relationship with being distinctive.

Consistency between existing product line and consistency with company image was 0.597 . The coefficient depicted that there is a strong and positive relationship between consistency with existing product line and consistency with company image. The probability (p) of this correlation coefficient which is 0.000 is less than 0.05 thus implying that there is a statistically significant relationship between consistency with existing product line and consistency with company image $(r=-0.597, p>0.05)$. The probability $(p)$ of this correlation coefficient which is 0.000 was less than 0.05 thus implying that there is a statistically significant relationship between ease of recall and ease of pronunciation $(r=-0.845, p>0.05)$. As discussed in the literature above, in the brand naming process, the ability to remember and easily pronounce the brand name is significant. The probability (p) of this correlation coefficient which was 0.000 is less than 0.05 thus implying that there was a statistically significant relationship between versatility for use with other products and carried well to other languages $(r=-0.810, p>0.05)$. Versatility in the context of this study refers to the multi-faceted use of the name which has an important relationship with being transferable across many languages as is found in the South African context where there are eleven official languages.

The correlation $(\mathrm{r}$ ) between outside trademark attorney and advertising agency was 0.197 . This coefficient showed a weak relationship between outside trademark attorney and advertising agency. The probability (p) of this correlation coefficient which is 0.105 is greater than 0.05 thus implying that there is no statistically significant relationship between outside trademark attorney and advertising agency ( $\mathrm{r}=-0.197$, $\mathrm{p}>0.05)$. Between advertising agency and marketing research agencies, it was found that probability (p) of this correlation coefficient which was 0.074 which is greater than 0.05 thus implying that there is no statistically significant relationship between advertising agency and marketing research agencies $(\mathrm{r}=-0.078$, $\mathrm{p}>0.05$ ).The correlation $(\mathrm{r})$ between specialized naming consulting firms and marketing/product/brand manager was 0.408. This coefficient showed that there was a strong and positive relationship between specialized naming consulting firms and marketing/product/brand manager. The probability (p) of this correlation coefficient which was 0.000 was less than 0.05 , implying that there is a statistically significant relationship between specialized naming consulting firms and marketing/product/brand manager $(\mathrm{r}=-0.408$, $\mathrm{p}>0.05$ ).

The correlation $(\mathrm{r}$ ) between senior marketing management and a select team of individuals from marketing was found to be 0.880 . This coefficient showed that there is a strong and positive relationship between senior 
marketing management and a select team of individuals from marketing. The probability (p) of this correlation coefficient which is 0.000 is less than 0.05 thus implying that there is a statistically significant relationship between senior marketing management and a select team of individuals from marketing $(\mathrm{r}=-$ $0.880, p>0.05$ ).The correlation ( $r$ ) between product development team and company legal counsel is 0.735 in the table below. This coefficient shows that there is a strong and positive relationship between product development team and company legal counsel. The probability (p) of this correlation coefficient which is 0.000 is less than 0.05 thus implying that there is a statistically significant relationship between product development team and company legal counsel $(r=-0.735, p>0.05)$.

The correlation $(\mathrm{r})$ between marketing research development department and the chosen brand name decided on because of what the business does is 0.033 . This coefficient shows that there is a weak relationship between marketing research development department and the chosen brand name decided on because of what the business does. The probability (p) of this correlation coefficient which is 0.764 is greater than 0.05 thus implying that there is no statistically significant relationship between marketing research development department and the chosen brand name decided on because of what the business does ( $\mathrm{r}=-$ 0.764, $\mathrm{p}>0.05$ ).These study results made it possible to rank these in the order of importance according to SMME practitioners. In Table 1 is the representation of these relationships is in accordance to SMMEs preferences, for ease of use, a relationship trait title has been coined for each. This table thus provides a qualitative summary of the results

Table 1: Trait Relationships Significance in Brand Naming for SMMEs

\begin{tabular}{|c|c|c|}
\hline $\begin{array}{l}\text { Order } \\
\text { Importance }\end{array}$ & Relationship Trait Title & Trait relationship significant in branding \\
\hline 1 & Recognizable and Likable & Ease of recognition \& Overall liking \\
\hline 2 & Language and Product Flexibility & $\begin{array}{l}\text { Versatility for use with other products \& Carriers } \\
\text { well to other languages }\end{array}$ \\
\hline 3 & Recallable and Easy to Enunciate & Ease of recall \& Ease of pronunciation \\
\hline 4 & $\begin{array}{l}\text { Based on product line and } \\
\text { Company Image }\end{array}$ & $\begin{array}{l}\text { Consistency with existing product line \& } \\
\text { Consistency with company image }\end{array}$ \\
\hline 5 & Different and Profane & Distinctive \&Profane or negative connotation \\
\hline 6 & $\begin{array}{l}\text { Product category } \\
\text { connotations }\end{array}$ & Relevance for product category \& Connotations \\
\hline
\end{tabular}

Source: Emerged from qualitative data, transformed from quantitative analysis

Quite a significant number of businesses did not respond to the question asking them to define their product offering. This could mean they were not aware of what their core product was, suggesting a lack of a fundamental skill in running a business which is defining, comprehending and articulate the core activities of one's business. It is quite interesting that according to this research, the most important reason for brand naming for these SMMEs seems to be the need to set oneself apart from competitors. Table 2, provides brand Naming Objectives. The largest valid percentages of the respondents, $27.3 \%$, felt that being easily identifiable was the main purpose to engage within the brand naming process. $24 \%$ of the respondents were driven by the need to establish product differentiation. This was followed by $21.3 \%$ who saw brand naming as a way to convey intended position. $12.7 \%$ engaged with brand naming in order to establish a distinct segment. Whilst $8.4 \%$ used it to establish a distinct image whilst $10.7 \%$ viewed the purpose to engage with brand naming processes necessary to make trading easier. Given these results however, it is important to note that 78.9 of the respondents responded. At no point in answering all questions regarding brand naming objectives did all respondents participate, it was only when the objective of identification was raised, the results showed the highest participation rate of 41 respondents which is $21.6 \%$. 
Table2: Brand Naming Objectives

\begin{tabular}{llllll}
\hline & & Frequency & Percent & Valid Percent & Cumulative Percent \\
\hline \multirow{6}{*}{ Valid } & Convey intended position & 32 & 16.8 & 21.3 & 21.3 \\
& Establish & product & & & \\
& differentiation & 36 & 18.9 & 24.0 & 45.3 \\
& Establish a distinct segment & 19 & 10.0 & 12.7 & 58.0 \\
& Establish a distinct image & 16 & 8.4 & 10.7 & 68.7 \\
& Identification only & 41 & 21.6 & 27.3 & 96.0 \\
& Ease of trade & 6 & 3.2 & 4.0 & 100.0 \\
& Total & 150 & 78.9 & 100.0 & \\
Missing & System & 40 & 21.1 & & \\
Total & & 190 & 100.0 & & \\
\hline
\end{tabular}

The implication revealed by the respondents behavior in dealing with brand naming objectives, could explain possibly a lack of knowledge about the concept of branding and their objectives. In Kohli and LeBahn (1995) process, the step that follows requires choosing a good pool of brand name alternatives; this did not seem to be the practice by SMMEs, differing from the concepts shared by Kohli and LeBahn (1995). When observing results from this study it is clear that this step is one that is not used nor considered. Only $13,2 \%$ of the SMME respondents admitted to relying on this method. Brainstorming was found to be used quite significantly for the brand naming process with $70.5 \%$ of respondents agreeing to use it for this purpose. For a strategy to exist, it is guided by objectives. Successful companies in their brand naming process use specific objectives. It is these objectives that are found to be fundamental in achieving success in the brand naming process, these are; Conveying intended position; establishing a product differentiation: Establishing a distinct image ; Identification and Ease of trade. Though the responses were low, SMMEs were only found to rate: Ease of trade, Identification and establishing a distinct image as important. Not realizing that all these are as important for a successful brand name to be established.

Brand naming custodian was other objective in study. In the literature above, Turley and Moore (1995) ask the question of who should carry the responsibility of branding naming. Theory identifies various sources for this function ranging from employees, trademark specialists, brand naming consultants, (Kohli \& LeBahn, 1995) to name but a few. The one source of this action mentioned by all who have written on the field of brand naming is the identification of the marketing departments as the custodian of the brand naming function, McNeal and Zaren (1981). This practice varied, other authors lend this responsibility to executive management and the marketing department. The empirical study assesses all the various roles of responsibility, ranging from consumers to specialists in branding and employees, to name but a few. With all these various possibilities probed, owners were found to be of more significance. With regard to other possible role players of importance in brand naming, the respondents did not answer at all, which raises the question of awareness and adequate skills or lack thereof which the SMME industry is marred by, as Dube (2001) purports. $44.7 \%$ of the respondents did not provide information about the highest education level passed which manifests the possibility of a lack of it. This would explain and support Dube (2001) who is of the notion that skills development is paramount to the development of SMMEs in South Africa. This suggests that there could be a country wide understanding of this phenomenon, still open to further investigation.

\section{Limitations of the study}

- It is necessary and imperative that a study assessing and defining the brand naming behavior be conducted with a greater sample from all regions of the country for it to be recognized as universal to South Africa.

- Use of a multivariate analysis method could have defined the relationship between demographics and the various traits better, towards the understanding of the brand naming strategies used by SMMEs. Therefore the methodology of this study could be regarded as limiting.

- Language was found to be pivotal when strategizing for brand naming processes though this variable is beyond the scope of this paper. It is essential to note for further research. In a country with eleven official languages, the most important trait to consider was that of ease of recall, followed by easy to pronounce, then transferability to other languages. All of these show that language usage is a great 
concern for SMMEs when brand naming. It seems to be the most important drive behind choice of brand.

\section{Conclusion and Recommendations}

The first research objective of the study which investigated brand naming strategies for SMMEs found that even though some of the vital traits and strategies were present, a majority of the vital one's were still not considered and possibly not known. The study reveals that Ease of trade, Business identity reasons, establishment of a distinct segment and image form part of the brand naming decision by SMMEs as they should. Embedded within the objectives was the existence of certain traits found to be important in this process, again for SMMEs there were concepts found to be lacking, specifically, positioning, which embodies the essence of branding and marketing. The second being product differentiation, a vital trait in brand strategy formulation therefore in the process of brand naming as well. The knowledge aspect is further supported by the fact that the results of this study, also reveal that most of these organizations cannot articulate what the core of their business is, which is a fundamental aspect in becoming efficient and effective in running a business and in identifying objectives.

A significant relationship was found creating variables that are important in the brand naming process by SMMEs. These were ranked into six traits as discussed in the results section, however, they lacked the variable that require resource investment which were, (1) Outside trademark attorney and (2) Marketing research agencies. The third objective of this study probed who the custodians of this process in SMMEs were? What was found was that SMME business owners made decisions without consultation on brand names. The use of other important stakeholders was not considered, i.e. the consumers, legal and other relevant experts in the field of branding and marketing. The question of resources is one that appears a number of times when reading the research results. This can firstly be seen when the question of who is responsible for the brand naming process. Even though SMMEs recognize the existence of important supplier organizations like agencies, trademark specialist, research agencies, etc, they are however not used. Given the turnover of most of these entities, the financial resource availability could be the reason for not using these entities in the brand naming process, as the owners are constantly attempting to bootstrap from the top of their head and not strategy. Again, the question of a lack of knowledge and skill is to blame, because if these organizations understood the financial power carried by a brand, they would in reality invest more on it and realize that brand naming and branding expenditure is in fact an investment for their organization.

Recommendations: Given the findings of this study, the following is advised and recommended:

- More branding and marketing programs which teach purpose and use of branding and their objectives need to be developed by both the private and public sector SMME training entities.

- There is a need for SMMEs to emulate the processes that are used by Large organizations this means investing resources in the brand naming process to hire the experts and expertise required by this process, i.e. use of attorneys, advertising agencies, purchase of certain assets, like existing brand names, amongst other possible brand names.

\section{References}

Aaker, D. A. (1996). Measuring Brand Equity Across products and Markets. California Management Review, 38(3), 102-120.

Abimbola, T. (2001). Branding As A Competetive Strategy for Demand Management in SMEs. Journal of Research in Marketing and Entrepreneurship, 3(1), 97-106.

Angus, E.\& Oppenheim, C. (2004). Studies of the characteristics of brand names used in the marketing of information products and services II: Internet related services. Retrieved from Loughborough Univeristy Institutional Repository: http://citeseerx.ist.psu.edu/viewdoc/download?doi=10.1.1.969.2587\&rep=rep1\&type=pdf

Babbie, E. \& Mouton, J. (2006). The Practice of Social Research (6 ed.). New York: Oxford University Press.

Berthon, P., Ewing, M. T. \& Napoli, J. (2008). Brand Management in Small to Medium Sized Enterprise. Journal of Small Business Management, 46(1), 27-45. 
Boyd, C. D. (1985). Point of View: Alpha-Numeric Brand Names. Journal of Advertising Research, 25(5), 48-52.

Brand, C. D., Du Preez, N. D. \& Schutte, C. (2007). A Business Framework to Network Small South African Enterprises for Sustainability. South African Journal of Industrial Engineering, 18(2), 187-201.

Cant, M., Gerber-Nel, C., Nel, D. \& Kotze, T. (2003). Marketing Research (1 ed.). Claremont: New Africa Books .

CIPC. (2016). What is IP. Retrieved from CIPC: www.cipc.co.za/index.php/trade-marks-patents-designscopyright/what-ip

Creswell, J. W. (2003). Research Design: Qualitative, quantitative and mixed method approaches. California: Sage Publications .

Crewell, J. W. (1994). Research Design-Qualitative \& Quantitative Approaches (1 ed.). California: Sage Publication Inc.

Dube, M. G. (2001). Government Agencies Under Fire in Enterprise: Where Black Business Lives (1 ed.). Johannesburg: CTP Book Printers.

Eku, D. E. (2007). Developing BDS Markets for the Poor: The Case for Community Based Eco Tourism. First RBI International Business Conference. Pretoria.

Frank , H. \& Altheon, S. C. (1994). Statistics-Concepts and Applications (Low Price Ed ed.). Cambridge: University Press .

GEM. (2014). An Alarmangly low level of entrepreneurial activity in spite of high unemployment. Retrieved from Gemconsortium: wwwgemconsortium.org/country-profile/108

Hair, J. F., Anderson, R. E., Tatham, R. L. \& Black, W. C. (1998). Multivariate Data Analysis (5 ed.). London: Prantice-Hall International.

Keller, K. L. (1998). The Brand Report Card. Havard Business Review, 147-156.

Keller, K. L. (2003). Strategic brand Management: Buidling Measuring and Managing Brand Equity. New Jersey : Prantice-Hall .

Kepferer, J. N. (2004). The New Strategic Brand Management. London: Kogan.

Kering, R. A. \& Sethuraman, R. (1998). Exploring the Brand-Value-Shareholder Value Nexus for Consumer Goods Companies. Academy of Marketing Science, 4, 260-273.

Kohli, C. \& LeBahn, D. W. (1995). Creating Effective Brand Names: a study of the Naming Process . ISBM.

Kohli, C. \& Suri, R. (2000). Brand Names That Work: A study of the Effectiveness of Different Types of Brand Names. Marketing Management Journal, 10(2), 112-120.

Kollman, T. \& Suckow, C. (2007). The Corporate Brand Name Process in the Net Economy. Qualitative Market Research International Journal, 10(3), 36-49.

Kotler, P. (2003). Marketing Insights from A-Z: 80 Concepts Every Manager Needs to Know. New Jersey: John Wiley \& Sons Inc.

Makhitha, K. M. (2009). The Importance of Appropriate Marketing Strategies for Craft Businesses. Wits Business School 2nd International Conference on Entrepreneurship .

Matveev, A. V. (n.d.). The Advantages of Employing Quantitative and Qualitative Methods in Intercultural Research: Practical Implications from the Study of the Perceptions of Intercultural Communication Competence by American and Russian Managers. Theory of Communication and Applied Communication (1).

McNeal, J. U. \& Zeren, L. M. (1981). Brand Name Selection for Consumer Products.MSU Business Topics, 35-39.

Meyer-Stamer, J. (2003). Stimulation Rural Enterprise in South Africa: Lessons from Local Economic Development. Stimulation Rural Enterprise Conference. Kempton Park.

Mthoba, F. (2004). Social Entrepreneurship: A Solution to Address the Challanges of the Second Economy. Social Entrepreneurship Conference and Exhibition. Gauteng.

Naidoo, B. (2008). EThekwini Seeks Economic Growth Salvation in Small Business Sector.Engineering News .

Naidoo, S. (2007). Why Small is Big in The Economy . Sunday Times-Business Times .

Parking, M., Powell, M. \& Mathews, K. (2008). Economics. Harlow: Pearson Education .

Phiri, M. A. (2009). Hindarances to Economic Success among Small, Medium and Micro Entrepreneurs involved in informal cross-border trade (ICBT) Between Malawi and South Africa. Business Management Conference. Durban.

Roszowski, M. J. (2013). Whats in A Name? : The Amateurs View of Good Practices in Naming an Online Education Program. Turkish Online Journal of Distance Education, 14(3), 225-240.

Sekeran, U.\& Bougie, D. (2010). Research Methods for Business: A Skills Buildig Approach. New York: John Wiley \& Sons Inc. 
Shipley, D., Hooley, G. J. \& Wallace, S. (1998). The Brand Name Development Process. International Journal of Advertising, 7, 253-266.

Stevenson, L. \& Lundstrom, A. (2001). Patterns and Trends in Entrepreneurship?SME Policy and Practice in ten economies. Entrepreneurship Polisy for the Future Series3. Stolkholm: Swedish Foundation for Small Business Research.

Struwig, M. (2011). THe Personal Financial Attitudes of SMME Business Owners in South Africa. Management in the New Economy Classic and Mondernity.

Turley, L. W. \& Moore, P. A. (1995). Brand Name Stratefies in the the Service Sector. Journal of Consumer Marketing, 12(4), 42-50.

Vanden Burgh, B., Adler , K. \& Oliver , L. (1987). Linguistic Distinction Among Top Brand Names. Journal of Advertising Research, 24, 39-44.

Visagie, J. C. (1997). E's Challanges in Reconstrucing South Africa. Management Decisions, 35(9), 660-667.

Wolpe, J. (1972). Capitalis, and Cheap Labout in South Africa: From Segregration to Apartheid. Economy and Society, I(4), 425-456.

Wong, H. Y. \& Merrilees, B. (2005). A Brand Orientation Typology for SME: A case Research Approach. Journal of Product and Brand Management, 14(3), 155-162. 